\title{
Impact of artificial illumination on the development of a leaf- mining moth in urban trees
}

\author{
Sibylle Schroer ${ }^{1 *}$, Eva Häffner², and Franz Hölker \\ ${ }^{1}$ Leibniz-Institut of Freshwater Ecology and Inland Fisheries, Müggelseedamm 310, 12587 \\ Berlin \\ ${ }^{2}$ Freie Universität Berlin, Botanischer Garten und Botanisches Museum Berlin, Königin- \\ Luise-Straße 6-8, 14195 Berlin
}

Received 30 August 2018, Accepted 13 August 2019

\begin{abstract}
Light emission from street lighting or other light sources alters the living conditions for organisms in urban areas. Nowadays, the impact of light at night (ALAN) on urban plants and their trophic environment is not well understood. To gain more insight about herbivore-plant interactions when exposed to ALAN, outdoor and greenhouse tests were conducted using the horse-chestnut leafminer, Cameraria ohridella, as a test organism due to its adaptive behavior.

At the end of the season, horse-chestnut seedlings infested with leafminers were exposed to two different light regimes in the greenhouse under short daylight conditions with nocturnal ALAN light levels of around 60 lx and control light levels of around 1.3 lx. After only one week, the mine size was lower on illuminated seedlings, presumably due to reduced leaf senescence. The leafminer developed a lower proportion of diapausing pupae and a higher proportion of free pupae, which leads to a further generation within the season.

Additionally, the development of chestnut tree leaves and the leafminer were measured at illuminated versus non-illuminated sites in the city of Berlin and the rural area of Brandenburg. Illuminated leaves were larger than those grown in darker rural areas and extended larval activity was recorded.

The results indicate an impact of ALAN on plant metabolism and on leafminer development and its larval activity. For urban trees the consequence might be an increased herbivore / parasite pressure. For herbivores and parasites less adapted to winter damages than the invasive leafminer reduced signals for winter dormancy due to ALAN could even threat the population.
\end{abstract}

Keywords: Aesculus hippocastanum, artificial light at night, light pollution, horse chestnut leafminer, diapause induction, dormancy

\section{Introduction}

Recent decades have been characterised by a profound transformation of nightscapes as a result of increasing night-time illumination [1,2]. The world's surface enlightens annually around 2 to $6 \%$, with a range of 0 to $20 \%$ $[2,3]$. In urban areas light levels can be up to 100 times brighter than in natural dark areas and atmospheric conditions such as cloud cover can profoundly change the brightness of urban nightscapes [4,5].

Effects of street lights on autumn leaf senescence of urban trees have already been shown in 1936 by Matzke et al. [6]. Furthermore, Cathy and Campbell (1975) [7] listed urban trees according to their sensitivity to artificial light at night (ALAN). Plants respond to their light environment with stomatal opening, chloroplast movement and individual growth pattern [8-10]. A growing number of studies indicate that light pollution has an effect on plants. Crops, ornamentals as well as wild plants can be affected by street light in growth [11], on

\footnotetext{
* Schroer, S, Tel.: +49-30-648 18-717; fax: +49-30-648 18-700

E-mail address: schroer@igb-berlin.de
} 
seasonality such as developmental delays [12], earlier bud burst [13] or delayed leaf senescence [14], in the composition of the living community [15], and in their metabolism, by impaired photosynthetic performance [16] and increased accumulation of radicals [17].

Street lighting is further known to interfere with insect plant interactions. Night time pollination is impaired due to the attraction of pollinators, such as moths, to light sources [18,19] and also night active herbivores, e.g. Mamestra brassicae or Operophtera brumata are attracted to street lights and affected in their progeny [20,21]. Vänninen et al. (2010) [22] describe in detail effects of artificial ligting on plant-insect interaction and point out that herbivores and beneficial arthropods as well as plant responses to these arthropods can be manipulated for better crop growth in greenhouses. However, little research has been performed on the impact of street light on the interaction of leaf development and larval herbivores or parasites in urban trees.

The intention of the present study was to understand if street light can have an effect on the seasonality of an urban tree and an associated leafmining moth. Cameraria ohridella Deschka and Dimic (Lepidoptera: Gracillariidae) and its main host, the white flowering horse chestnut (Aesculus hippocastanum), were used as test organisms. The horse chestnut tree is native to mixed forests in Southeast-Balkan and widely cultivated in streets and parks all over temperate Europe. The trees are greatly affected by the miner with regards to both aesthetics and plant's health. Since the 1990s the invasive moth spread rapidly over Europe [23], with an estimated tenfold population growth per generation, when conditions are favourable [24]. The miner usually develops five instars and up to three generations within one season, according to summer temperature. In warm lowland regions of southern Europe up to five generations were observed [25]. After the fifth instar the larvae either develop into pupae, which go dormant for 12-16 days, or into diapausing pupae, which go in dormancy for at least six months. The latter are mainly developed by the last generation of the season [26]. Additionally, a small percentage of larvae of each earlier generation develop pupae for winter dormancy. The nutritional quality of the host leaf is the determining factor for the quantity of larvae that develop into winter diapausing pupae [27]. Short and long time diapausing pupae can be distinguished by the firmness of their cocoons. Short diapausing pupae within the generations of one season develop soft net cocoons, and winter dormating pupae are cocooned in firm covers. The horse chestnut leafminer is present everywhere in Berlin and rural areas of Brandenburg and greatly adaptive to changing environmental conditions [28], therefore offering ideal conditions to study responses to artificial light at night exposure.

Our greenhouse and outdoor studies allowed us to test two hypotheses, namely (i) that leaves treated with additional ALAN are going into senescense later in the season, will potentially bear a higher content of nutrition for a longer period and therefore might allow the leaf miner to develop a further generation; and (ii) that street light can delay the seasonality in urban trees and therefore might alter the development of parasites, like $C$. ohridella

\section{Material and Methods}

\section{$2.1 \quad$ Greenhouse Studies}

At the end of the season, infested chestnut tree seedlings were obsereved in two greenhouse chambers, one with and one without ALAN. At the end of October, the first batch with 14 horse-chestnut seedlings infested with leafminers was purchased from the $C$. ohridella cultivar of the plant protection department Berlin. The seedlings were exposed to adult moths for $48 \mathrm{hrs}$ at $20^{\circ} \mathrm{C}$ under long-day conditions (16 hrs artificial illumination). The resulting infestation number was approximately $1.5( \pm 1.4)$ larvae per leaflet.

After infestation, the seedlings were divided into the two cabins. The greenhouse was not heated, temperature was at approximately $8-15^{\circ} \mathrm{C}$ in both chambers. One half was kept under short-day light conditions with 8 hrs supplementary lighting during daytime (Philips Master Son-T, 600W); the other half was held at the same conditions with additional illumination using warm-white energy-saving lamps (Megaman, 18W) for 24 hrs. The plants that received additional illumination during the whole night are herein refered to as "illuminated" the plants that were kept without additional illumination during the night are herein referred to as "non-illuminated".

The brightness was measured at 12 points within the canopy using ILT1700 research radiometer (range: 0.00167-1,670,000 1x), from International Light Technologies (Peabody, MA) with an SUD033/Y/W silicon detector with photopic filter (400-700 nm, photopic calibration). Nocturnal brightness at the plant canopy was about $59.87( \pm 40.54)$ lux or $0.838( \pm 0.568) \mu \mathrm{mol}$ photons $\mathrm{m}^{-2} \mathrm{~s}^{-1}$ at the illuminated chamber and about 1.31 $( \pm 0.95)$ lux or $0.018( \pm 0.013) \mu \mathrm{mol}$ photons $\mathrm{m}^{-2} \mathrm{~s}^{-1}$ at the non-illuminated chamber. 
The size of the leaflets and the number of mines were recorded at the beginning of the experiments. The mine area was measured weekly for four and six weeks, respectively, using a hand held ruler. Leave senescence was visually compared and recorded. At the final examination, the mines were opened to assess the developmental stage of the moths. One week after the first, a second batch with 10 plants infested with approximately $6.1( \pm 8.2)$ larvae per leaflet was started. The mines were finally examined only after 11 weeks, because of slower larval development due to decreased temperatures $\left(8-12^{\circ} \mathrm{C}\right)$.

We compared the size of the leaves and the number of mines, larvae, and pupae in single leaflets, using the software package SPSS. We used single leaflets as independent replicates, because horse chestnut tree leaf miners stay in their larval phase within the area of one leaflet and the development of the miner is dependent on the conditions of the single leaflet. The eggs of $C$. ohridella are laid individually and not in a batch, therefore zero inflated effect models were neglected. All of the larvae were potentially able to develop into free pupae or winter diapausing cocoons, we therefore compared the developing stage of $C$. ohridella in a Shapiro-Wilk test on normal distribution. Both, mine size and developmental stages were not normally distributed; therefore the significance was calculated using the non-parametric two-sided Mann-Whitney-U-test. The threshold for significance was $\mathrm{p}<0.05$.

\subsection{Outdoor Studies}

At the end of the season, in Mid-October, infested leaves were collected outdoors from seven sites directly illuminated by street lights (referred to herein as "illuminated sites") versus nine sites without direct illumination (referred to herein as "dark sites") in the city of Berlin and the rural area of Brandenburg. Illuminated and dark sites were of comparable infrastructure. The illumination levels were also measured with the same ILT1700 research radiometer as described at greenhouse studies. From each tree, five to ten leaves were analyzed. The size of the leaves, leafminer infestation and its developmental stages were recorded. To confirm the data, we repeated the test at three different sites in the end of October of the following year. We chose illuminated sites in Berlin and Brandenburg and a dark site in Brandenburg. At this collection date 12 leaves per site from three different trees were collected.

We compared the size of the leaves, the number of mines, larvae, and pupae, using the software package SPSS. The size of the leaves and the developmental stage of $C$. ohridella were compared at illuminated vs. dark sites in Berlin and Brandenburg, illuminated vs. dark sites seperately in Brandenburg and Berlin, and all sites in Berlin vs. all sites in Brandenburg. Except for the leave size, the data were not normally distributed; therefore, significance was tested using the non-parametric two-sided Mann-Whitney-U-test. The threshold for significance was $\mathrm{p}<0.05$.

\section{Results}

\section{$3.1 \quad$ Greenhouse Studies}

Illuminated seedlings held significantly smaller $C$. ohridella mines than the non-illuminated ones. After the first week, the size of the mines differed significantly by approximately $15 \mathrm{~mm}^{2}(\mathrm{p} \leqslant 0.05, \mathrm{~F}=1.374, \mathrm{dF}=565)$. The mine size was $121.38 \mathrm{~mm}^{2}\left( \pm 82.30\right.$ at illuminated and $136.92 \mathrm{~mm}^{2}( \pm 79.59)$ at non-illuminated leaves. Two weeks later, the difference was $>50 \mathrm{~mm}^{2}$ with $224.83 \mathrm{~mm}^{2}( \pm 96.08)$ median mine size at illuminated leaves and $277.38( \pm 90.89)$ median mine size at dark leaves $(\mathrm{p} \leqslant 0.001, \mathrm{~F}=1.946, \mathrm{df}=387)$. By the end of December, senescence of the leaves was visibly advanced at non-illuminated seedlings, but not visually perceivable at illuminated leaves.

The development of the leafminers differed greatly between illuminated and non-illuminated seedlings (Fig. 1). The number of miners that developed to free pupae at the illuminated plants was twofold higher than at the non-illuminated plants $(\mathrm{p} \leqslant 0.001)$. Accordingly, the number of developed diapausing pupae was twofold lower at the illuminated plants $(\mathrm{p} \leqslant 0.014)$. 


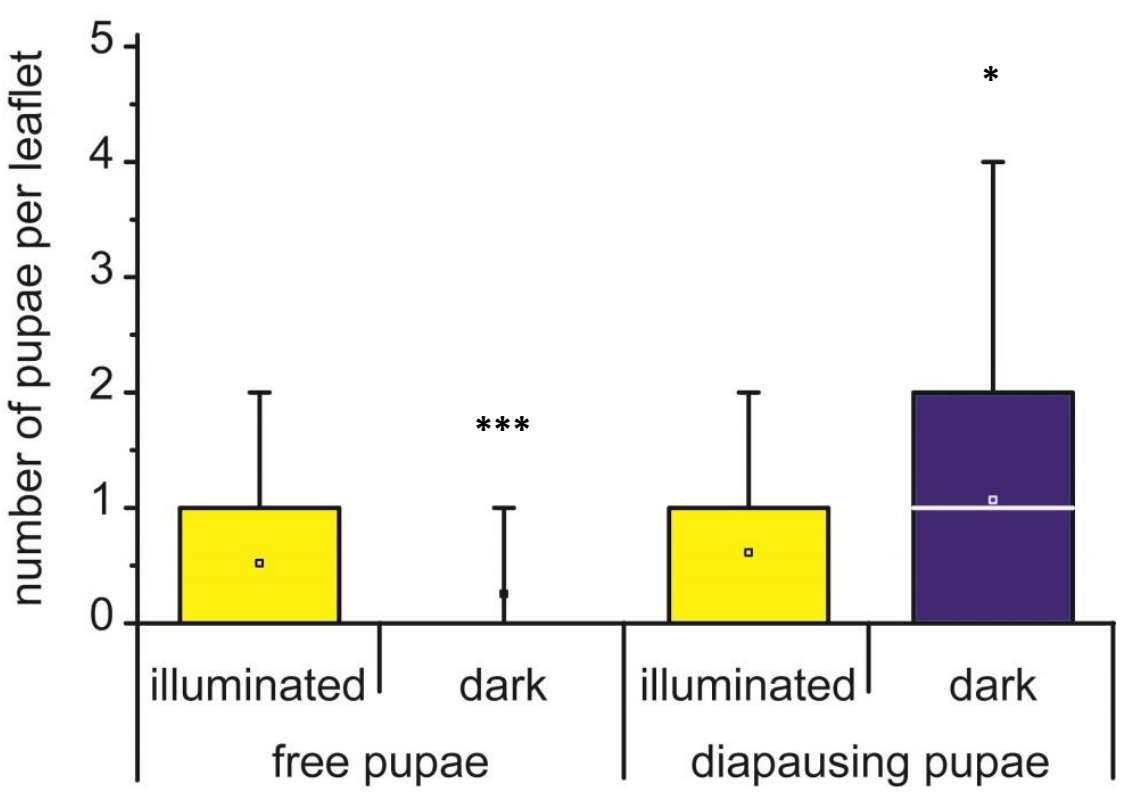

Fig. 1: Mean number of free and diapausing horse chestnut leafminer pupae. Horse chestnut seedlings were infested at the end of October with a mean number of 1.5 miners per leaflet. The number of pupae was recorded from single leaflets after 6 weeks treated with (N=98) and without $(\mathrm{N}=102)$ artificial illumination at night at $8-15^{\circ} \mathrm{C}$. Range of boxes gives 25 to 75 percentile, of whiskers 5 to 95 percentile. Numbers were compared using non-parametric Mann-Whitney-U-test. Significant differences are indicated with $*(\mathrm{p}<0.05)$ and $* * *(\mathrm{p}<0.001)$, respectively.

The second batch was examined in January, four weeks after the first. At this time, the majority of leafminers has developed into diapausing pupae under both light regimes (Median of 2 in the illuminated vs 3 in the nonilluminated seedlings, difference not significant). This was presumably due to a stronger signal for dormancy because of a lower greenhouse temperature in the winter months and reduced daylight. However, whereas free pupae were only sporadically found in the non-illuminated seedlings (Median=0), the illuminated seedlings still contained about one free pupa per leaflet (Median=1). The difference was significant $(\mathrm{p} \leqslant 0,001$, Mann-Whitney $\mathrm{U}$ test). In the second batch. The most conspicuous difference was found in the number of active larvae: 42 larvae have been detected on the illuminated plants vs. one single larva on the non-illuminated seedlings. The difference was significant $(0 \leqslant 0,001$, Mann-Whitney U-test $)$

\subsection{Outdoor Studies}

In the outdoor studies, an average of 96 mines, 7 pupae and 6 larvae per leaf were recorded. The most conspicuous difference was the number and density of still active larvae (Fig. 2A). The number of active larvae was significantly lower at non-illuminated sites in the rural areas $(\mathrm{p} \leq 0.005, \mathrm{~F}=0.785, \mathrm{dF}=97$ and $\mathrm{p} \leq 0.28$, $\mathrm{F}=0.753, \mathrm{dF}=97$, respectively). Illuminated leaves were found to be larger than non-illuminated ones $(\mathrm{p} \leq 0.012)$ (Fig. 2B). This difference was significant in Brandenburg $(\mathrm{p} \leq 0.031)$, but not in Berlin $(\mathrm{p} \leq 0.164)$. The size difference of leaves from Berlin compared to those from Brandenburg, independent of direct illumination was insignificant $(\mathrm{p} \leq 0.170)$. The number of mines was higher at illuminated than at dark sites $(\mathrm{p} \leq 0.018)$. The mine density, taking into account the differences in leaf size, did not differ significantly between illuminated and nonilluminated sites (Fig. 2C). However, the mine density was significantly higher in Brandenburg compared to Berlin regardless to the illumination level at the site. 
$\mathrm{N}: \quad 25$

A: active larvae per $\mathrm{cm}^{2}$

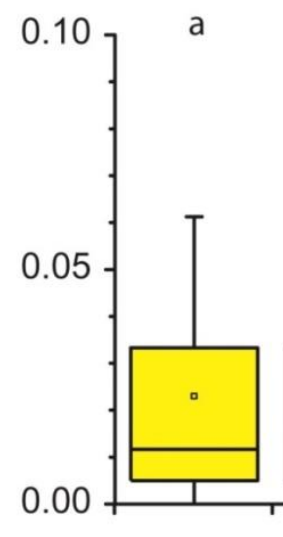

a

a

b

B: leaf size $\left[\mathrm{cm}^{2}\right]$

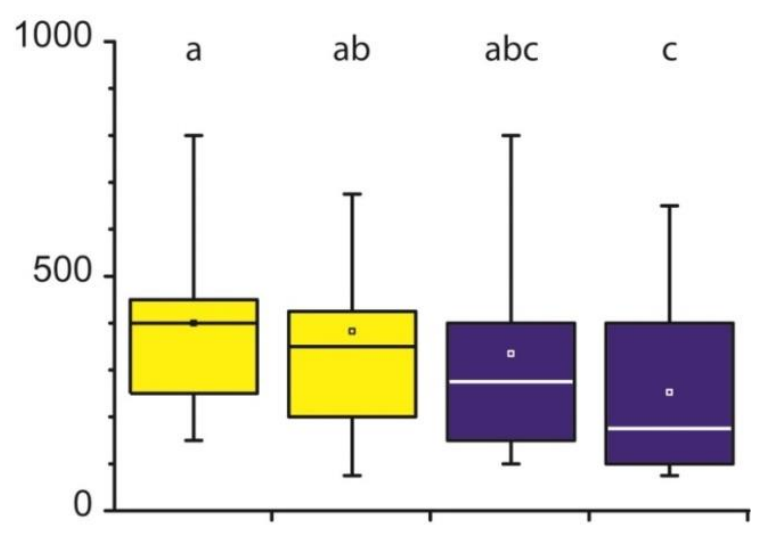

C: mines per $\mathrm{cm}^{2}$

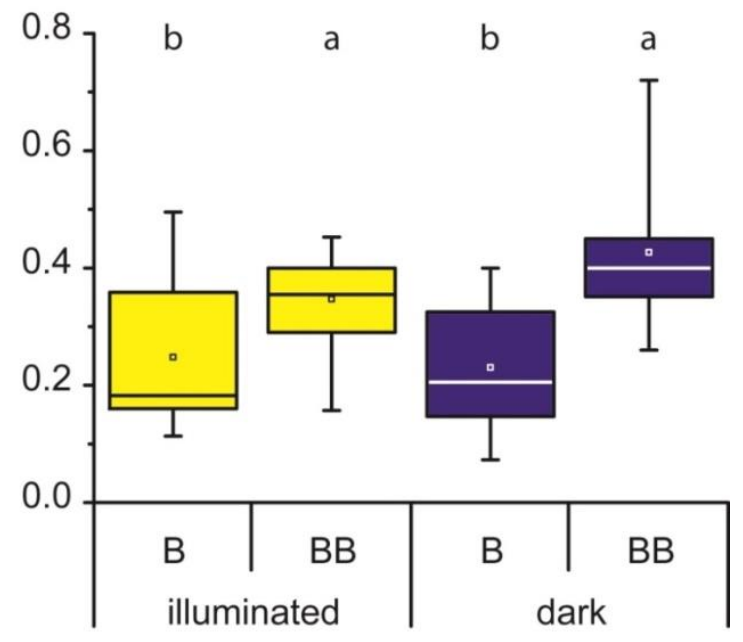

Fig. 2: Presents mean number of (A) still active larvae per $\mathrm{cm}^{2}$ leaf, (B) the leaf size and (C) the density of mines / $\mathrm{cm}^{2}$. Data was recorded from horse chestnut leaves, which were collected from illuminated versus not directly illuminated (dark) sites in the city of Berlin (B) and the rural area of Brandenburg (BB). Range of boxes gives 25 to 75 percentile, whiskers 5 to 95 percentile. Numbers were compared using non-parametric Mann-Whitney-U-test. Significant differences are indicated with variable letters $(\mathrm{p}<0.05)$.

In October of the following year, we collected leaves only from illuminated and dark trees in Brandenburg and from illuminated trees in Berlin, but not from dark sites in Berlin, because no difference was recorded previously at illuminated and dark sites within the city. The recorded data was in accordance with the previous findings (Table 1). The leaf size was smaller at the dark site in Brandenburg, and the percentage of active larvae was increased in the city (80\%) compared to the illuminated site in Brandenburg (19\%), which in turn showed significantly more active larvae than the dark site in Brandenburg (8\%). In contrast to the previous year, fewer active larvae were found in the illuminated trees in Brandenburg than in Berlin. 
Table 1: Mean size (SD) of collected horse chestnut leaves $(n=12)$, the number of living horse chestnut leafminer (HCM) per leaf, the distribution of larvae and pupae, the percentage of larvae and the number of larvae per $\mathrm{cm}^{2}(\sigma)$. Leaves were collected in an illuminated schoolyard in the city of Berlin (B) and at two similar rural locations in Brandenburg (BB) one was illuminated with mercury vapor street lights the other was without direct illumination. Data was collected at the end of October.

\begin{tabular}{ccccccc}
\hline Location & Leaf size $\left(\mathbf{c m}^{2}\right)$ & HCM per leaf & Pupae per leaf & Larvae per leaf & Larvae $(\%)$ & Larvae $/ \mathbf{c m}^{2}$ \\
\hline B, illuminated & $250.65(60.37) \mathrm{a}$ & $22.33(9.92) \mathrm{ab}$ & $4.00(1.14) \mathrm{b}$ & $17.02(2.08) \mathrm{a}$ & $79.63(2.89) \mathrm{a}$ & $0.08(0.04) \mathrm{a}$ \\
\hline $\mathrm{BB}$, illuminated & $262.67(85.43) \mathrm{a}$ & $27.42(10.58) \mathrm{a}$ & $22.75(3.63) \mathrm{a}$ & $4.67(0.63) \mathrm{b}$ & $18.81(3.38) \mathrm{b}$ & $0.02(0.02) \mathrm{b}$ \\
\hline BB, dark & $130.91(54.40) \mathrm{b}$ & $17.92(13.38) \mathrm{b}$ & $16.92(7.77) \mathrm{a}$ & $1.00(0.66) \mathrm{c}$ & $8.10(4.96) \mathrm{c}$ & $0.01(0.01) \mathrm{c}$ \\
\hline
\end{tabular}

Letters indicate significant differences within the columns (Mann-Whitney-U-Test, $\mathrm{p}<0.05$ ).

\section{Discussion}

The results of both, the greenhouse and the outdoor studies, confirm our hypothesis that leaf senescence is delayed by ALAN and that the better leave quality can potentially lead to a further generation of the horse chestnut leafminer in late autumn.

\subsection{Light pollution and urban trees}

Street light, can delay leaf fall of trees $[6,7,14]$. In this study a delay of leaf senescence in horse chestnut seedlings was observed in the greenhouse, supporting our hypothesis. Furthermore, leaves collected outdoors from urban sites and from illuminated rural sites were found to be bigger in size compared to rural, nonilluminated leaves. Factors for leaf size were recently described in a geo-spatial context to be determined by daytime and nighttime leaf-to-air temperature differences, nutritional availability and radiation exposure [29].

The insignificant difference of leave sizes between illuminated and non-illuminated sites within the city might be due to the so called skyglow effect. Radiation of different light sources are reflected by atmospheric particle and can amplify the night time brightness of an area in intensity and extend by multiple times, especially when cloud coverage increases the atmospheric reflection [5]. We listed the measured radiation at the study sites in Brandenburg and Berlin, using the data from VIIRS-DNB (Visible Infrared Imaging Radiometer Suite Day/Night Band, recorded on November 2015) and the approximate temperature differences in the city and the rural sites, using data obtained from the German weather service (Table 2). The differences in temperature were approximately two degrees between Berlin and Brandenburg. Differences in the radiation, measured with the photometer, were approximately $0.135-0.270 \mu \mathrm{mol} \mathrm{m} \mathrm{m}^{-2} \mathrm{~s}^{-1}$. The overall night time brightness measured by the satellite sensor presents up to 30 times brighter values in the city than in the rural areas. In Brandenburg we find a comparatively low background noise of night time brightness due to the lower density of lighting points. The contrast between the illuminated and non-illuminated sites therefore are more pronounced at the darker rural sites, suggesting that skyglow in combination with higher average temperature potentially can impact plants e.g. inducing greater leave size and delaying senescence. However, the presented data are insufficient to attribute the effect of increased leaf growth to the skyglow effect alone. But, as direct street light has an effect on the timing for defoliation [6,14], can reduce nighttime respiration [17] and worsen the foliar condition in impairing the circadian rhythm of starch metabolism and stomatal activity [30] it is important to further clarify if skyglow can have an impact on plant metabolism.

This is especially important as recently Pretsch et al. (2017) found in a global study on tree ring analyses in ten metropolises accelerated tree growth and aging in urban areas since the 1960s [31] The authors attribute the altered aging of trees primarily to increased temperature due to climate change and heat islands in cities, and secondly to higher atmospheric $\mathrm{CO}_{2}$-content and fertilization due to $\mathrm{N}$-deposition. We argue that next to temperature trees are furthermore exposed to increasing night time brightness. The significantly accelerated tree growth rate from the 1960s onward might also be reasoned by the invention and increasing use of gas-discharge street lighting with high efficacy above $100 \mathrm{~lm} / \mathrm{W}$ at this time [32]. 
Table 2: Average temperature and brightness ranges at the test sites in Berlin and Brandenburg.

\begin{tabular}{|c|c|c|c|c|c|c|}
\hline \multirow{2}{*}{ Test sites } & \multicolumn{3}{|c|}{$\begin{array}{c}\text { Average annual temperature }\left({ }^{\circ} \mathrm{C}\right) \\
\text { Years } 2012-17^{*}\end{array}$} & \multicolumn{2}{|c|}{$\begin{array}{c}\text { Photometer measurement (lux) } \\
\text { (standard deviation) }\end{array}$} & \multirow{2}{*}{$\begin{array}{l}\text { VIIRS-DNB } \\
\text { data range } \\
\left(\mathrm{nW} / \mathrm{cm}^{2} / \mathrm{sr}\right) \\
(2015)\end{array}$} \\
\hline & $\min$. & $\max$ & average & illuminated & dark & \\
\hline Berlin & -1.3 & 19.5 & 10.7 & $13.5(20)^{* *}$ & $1.4(4.6)^{* *}$ & $10-30$ \\
\hline Brandenburg & -2.2 & 18.3 & 8.7 & $25.1(9.6)^{* *}$ & $0.4(0.4)^{* *}$ & $1-6$ \\
\hline
\end{tabular}

*temperature average per month according to https://www.wetterkontor.de/

** photometer measurement $(\mathrm{N}=3)$ in the horizontal at leave canopy at overcast sky and new moon, 22:00-23:00h

\subsection{Impact of light pollution on host-parasite and-herbivore relations}

With this study we demonstrate for the first time to our knowledge that the horse chestnut leafminer can potentially develop a further generation in urban and illuminated rural trees in late October when conditions are favourable. Night time illumination might improve conditions for larval activity and food supply and thus extended leafminer activity into winter months. The multivoltism allows the leafminer to increase the net population growth rate [33]. An additional generation might allow $C$. ohridella to build up outbreaking population numbers and infest the tree to a higher extent in the next year. Early infestation due to high abundance of overwintering leafminer pupae can lead to a stronger negative impact on the trees [34]. The measured lower mine density in Berlin versus Brandenburg in our study, might be the result of successful control efforts in Berlin (e.g. removal of fallen leaves in autumn) [28] and neither related to the illumination nor to temperature.

In the event of sudden frost and leave fall the population of horse-chestnut leafminer is well protected due to the ratio of pupae that go into winter dormancy in each earlier generation. The first generation in the following season remains therefore highly abundant even when winter mortality is above $90 \%$ [24]. Herbivores, parasites and beneficials, such as parasitoids, on the other hand, might as well perceive a weaker signal for winter dormancy, when trees are illuminated by street lights and start senescence later. Insects that are less adapted to sudden frost events might be threatened, when they lack the signal for dormancy. Artificial light could therefore reduce the genetic diversity in being of advantage to species that can well adapt to light, but possibly reducing genetic variation of species, which rely on strong day-night rhythms.

Insect decline is a severe phenomenon in recent decades discussed by several studies [35, 36]. Hallmann et al. (2016) [36] name pesticides and land use change as the main factors for the decline, but Grubisic et al. (2018) [37] point out on the artificial brightening within the study sites and discuss light pollution to be an often overseen but undeniable factor in insect decline. The findings of Langenvelde et al. (2018) [38] that the most threatened Lepidoptera species are night-active and highly light sensitive, underline this argument.

Furthermore, the distribution and extended horse-chestnut leafminer activity were never discussed to be due to a possible attraction to artificial light by the adult moths, but solely to increased temperature in the cities [24]. Augustin et al. (2009) discuss human transportation for long distance dispersal of $C$. ohridella and mention first appearance of the leafminer in cities close to car parks and railway stations [39]. The authors neither mention light as a relevant factor, although infrastructural areas can emit the highest ratios of ALAN [40]. Street lights can drive community structure in ecosystems [e.g 41,42]. They can attract insects in high quantity, but the number of species in the vicinity of the light is actually declining [19]. Such illuminated ecosystems may be more prone to invasion because they have more likely "open" niches for invasive species and may lack natural competitors and predators to control them.

\subsection{Solutions for lighting planners and authorities}

Street light and illumination of trees can alter the metabolism [17,31], the seasonality [13,14] the ecological functioning of associated insects [18] and thus the tritrophic system. Although the total avoidance of illumination could be the only measure to protect all organisms of a living community from the negative impact of ALAN [e.g. 41], the arguments for environmental protection do not play the sole role in lighting planning. To mediate between claims for the enviroment and those for aesthetiscs and security, it is recommended to install outdoor illumination, that is limited in intensity and time [41] as well as in the ratio of short wavelength light 
(blue light and UV-radiation) [43]. Hogewoning et al. (2010) point out that plant illumination with about 7\% blue light ratio in the spectral power distribution can already be sufficient to trigger photosynthesis and thus plant metabolism outside of the natural day-light rhythm [44]. Furthermore, blue enriched LED-light can excellerate bud burst in spring [45]. Likewise to plants, short wavelength lighting can potentially have higher impact on the attraction of insects [46]. The broader the light spectrum of outdoor lighting, the higher its potential to affect insects [44,47]. The ongoing trend to use white outdoor lighting and the global increase of illumination in radiation and extend [2] is making regulations for outdoor illumination an urgent and timely issue. Such regulations for the protection of flora and fauna need to consider the lighting colour, intensity and light distribution as well as the temporal and spatial extent of illumination equivalently [47]. Negative impact of ALAN can be reduced by:

(a) Optimizing the radiation geometry, directing the light only to where it is needed, limiting stray light outside of the target area, especially avoiding radiation into biotops like urban trees and other green areas.

(b) Limiting the intensity and time period of illumination.

(c) Adapting the spectral composition to the environmental context. For example, illumination for aesthetic reasons in urban greens could be limited to the use of narrow band light of green, or red wavelengths.

\section{Conclusion}

The impact of outdoor lighting on urban trees and their trophic environment has so far been underrespresented in research. Artificial light at night needs to be considered as a potential impact factor for urban organsisms likewise to temperature, land use or pollutants of the air, soil and water. It can interfere with the circadian rhythm of urban trees, thus disturbing the trophic environment and resulting in reduced signals for winter domancy. Adaptation to light at night conditions might be only beneficial to some adaptative species and could in general lead to a change or even loss in biodiversity.

Sustainable lighting planning and regulations for outdoor illumination could reduce the negative effects on urban trees and their trophic interaction. And, in protecting urban trees, two further stressors for urban wildlife can be reduced, the global warming effect and air pollution, because trees metabolise $\mathrm{CO}_{2}$, absorb certain pollutants and improve the micro climate of their environment. The regulation of illumination is thus an important conservation measure and by far easier to obtain, than the regulation of outdoor temperature.

The present study is pointing out that further research is urgently needed to measure the extent to which ALAN can interfere with the trophic environment of trees. This research is a necessary basis to develop and establish measures for reducing ALAN-induced pressure on urban wildlife and to protect biodiversity. Furthermore, the interactions between increasing temperatures due to climate change and increasing brightness of nightscapes require more scientific attention in order to protect ecosystems and their services. The definition of thresholds at which plants and arthropods can be affected at certain temperatures, can help to regulate outdoor illumination in a sustainable way.

\section{Acknowledgements}

This article is dedicated to the memory of two great scientists, Prof. Abraham Haim and Prof. Thomas Posch, from the loss of the night network (EU-COST Action ES1204). The work was supported by MILIEU (Freie Universität Berlin) and by the project STARS4ALL' (funding from the European Union's Horizon 2020 research and innovation programme-under grant agreement No. 688135). We are very grateful to the JuliusKühn Institute for providing greenhouse facilities and to Barbara Jäckel (Plant Protection Department), Roy van Grunsven (Dutch Butterfly Conservation), Monika Hilker and Torsten Meiners (Applied Zoology, Freie Universität Berlin) for their help and support. Technical assistance of Doreen Vollandt is gratefully acknowledged. We are thankful for editing of the English language by Catherine Pérez Vega.

\section{References}


[1] Falchi, F., Cinzano, P., Duriscoe, D., Kyba, C. C., Elvidge, C. D., Baugh, K., ... \& Furgoni, R. (2016). The new world atlas of artificial night sky brightness. Science advances, 2(6), e1600377.

[2] Kyba, C. C., Kuester, T., De Miguel, A. S., Baugh, K., Jechow, A., Hölker, F., ... \& Guanter, L. (2017). Artificially lit surface of Earth at night increasing in radiance and extent. Science advances, 3(11), e1701528.

[3] Hölker, F., Moss, T., Griefahn, B., Kloas, W., Voigt, C. C., Henckel, D., ... \& Franke, S. (2010). The dark side of light: a transdisciplinary research agenda for light pollution policy. Ecology and Society, 15(4).

[4] Kyba, C. C., Tong, K. P., Bennie, J., Birriel, I., Birriel, J. J., Cool, A., ... \& Ehlert, R. (2015). Worldwide variations in artificial skyglow. Scientific reports, 5, 8409 .

[5] Kyba, C. C., Ruhtz, T., Fischer, J., \& Hölker, F. (2011). Cloud coverage acts as an amplifier for ecological light pollution in urban ecosystems. PloS one, 6(3), e17307.

[6] Matzke, E. B. (1936). The effect of street lights in delaying leaf-fall in certain trees. American Journal of Botany, 23(6), 446-452.

[7] Cathey, H. M., \& Campbell, L. E. (1975). Security lighting and its impact on the landscape. Journal of arboriculture.

[8] Keller, M. M., Jaillais, Y., Pedmale, U. V., Moreno, J. E., Chory, J., \& Ballaré, C. L. (2011). Cryptochrome 1 and phytochrome B control shade-avoidance responses in Arabidopsis via partially independent hormonal cascades. The Plant Journal, 67(2), 195-207.

[9] Briggs, W. R., \& Christie, J. M. (2002). Phototropins 1 and 2: versatile plant blue-light receptors. Trends in plant science, 7(5), 204-210.

[10] Schroer, S., \& Hölker, F. (2017). Impact of lighting on flora and fauna. Handbook of advanced lighting technology, 957-989.

[11] Sinnadurai, S. (1981). High pressure sodium street lights affect crops in Ghana. World crops.

[12] Palmer, M., Gibbons, R., Bhagavathula, R., Davidson, D., \& Holshouser, D. (2017). Roadway Lighting's Impact on Altering Soybean Growth: Volume 1. Illinois Center for Transportation/Illinois Department of Transportation.

[13] Ffrench-Constant, R. H., Somers-Yeates, R., Bennie, J., Economou, T., Hodgson, D., Spalding, A., \& McGregor, P. K. (2016). Light pollution is associated with earlier tree budburst across the United Kingdom. Proceedings of the Royal Society B: Biological Sciences, 283(1833), 20160813.

[14] Massetti, L. (2018). Assessing the impact of street lighting on Platanus x acerifolia phenology. Urban forestry \& urban greening, 34, 71-77.

[15] Bennie, J., Davies, T. W., Cruse, D., Bell, F., \& Gaston, K. J. (2018). Artificial light at night alters grassland vegetation species composition and phenology. Journal of applied ecology, 55(1), 442-450.

[16] Meravi, N., \& Kumar Prajapati, S. (2018). Effect street light pollution on the photosynthetic efficiency of different plants. Biological Rhythm Research, 1-9.

[17] Kwak, M., Je, S., Cheng, H., Seo, S., Park, J., Baek, S., ... \& Kim, H. (2018). Night light-adaptation strategies for photosynthetic apparatus in yellow-poplar (Liriodendron tulipifera L.) exposed to artificial night lighting. Forests, 9(2), 74.

[18] Knop, E., Zoller, L., Ryser, R., Gerpe, C., Hörler, M., \& Fontaine, C. (2017). Artificial light at night as a new threat to pollination. Nature, 548(7666), 206.

[19] Macgregor, C. J., Evans, D. M., Fox, R., \& Pocock, M. J. (2017). The dark side of street lighting: impacts on moths and evidence for the disruption of nocturnal pollen transport. Global Change Biology, 23(2), 697707.

[20] van Geffen, K. G., van Eck, E., de Boer, R. A., van Grunsven, R. H., Salis, L., Berendse, F., \& Veenendaal, E. M. (2015). Artificial light at night inhibits mating in a Geometrid moth. Insect Conservation and Diversity, 8(3), 282-287.

[21] van Geffen, K. G., van Grunsven, R. H., van Ruijven, J., Berendse, F., \& Veenendaal, E. M. (2014). Artificial light at night causes diapause inhibition and sex-specific life history changes in a moth. Ecology and Evolution, 4(11), 2082-2089.

[22] Vänninen, I., Pinto, D. M., Nissinen, A. I., Johansen, N. S., \& Shipp, L. (2010). In the light of new greenhouse technologies: 1. Plant-mediated effects of artificial lighting on arthropods and tritrophic interactions. Annals of Applied Biology, 157(3), 393-414.

[23] Valade, R., Kenis, M., Hernandez-Lopez, A., Augustin, S., Mari Mena, N., Magnoux, E., ... \& LopezVaamonde, C. (2009). Mitochondrial and microsatellite DNA markers reveal a Balkan origin for the highly invasive horse-chestnut leaf miner Cameraria ohridella (Lepidoptera, Gracillariidae). Molecular Ecology, 18(16), 3458-3470.

[24] Sefrova, H. (2001). Dispersal of the horse-chestnut leaf miner, Cameraria ohridella Deschka \& Dimic, 1986 in Europe: its course, way and causes. Entomol Z, 111, 194-198.

[25] Hellrigl, K. (2001). Neue Erkenntnisse und Untersuchungen über die Rosskastanien-Miniermotte Cameraria ohridella Deschka \& Dimic, 1986 (Lepidoptera, Gracillariidae). Gredleriana, 1(2001), 9-81.

[26] Pschorn-Walcher, H. (1994). Freiland-Biologie der eingeschleppten Roßkastanien-Miniermotte Cameraria ohridella Deschka et Dimic (Lep., Gracillariidae) im Wienerwald. na.

[27] Samek, T. (2003). Diapause of Cameraria ohridella Deschka et Dimic and its impact on the species population dynamics. J. Forest Sci, 49, 252-258.

[28] Balder, H., \& Jäckel, B. (2003). Die Kastanienminiermotte und mögliche Gegenmassnahmen. Stadt+ Grün, 5, 44-49.

[29] Wright, I. J., Dong, N., Maire, V., Prentice, I. C., Westoby, M., Díaz, S., ... \& Leishman, M. R. (2017). Global climatic drivers of leaf size. Science, 357(6354), 917-921. 
[30] Kwak, M. J., Lee, S. H., Khaine, I., Je, S. M., Lee, T. Y., You, H. N., ... \& Woo, S. Y. (2017). Stomatal movements depend on interactions between external night light cue and internal signals activated by rhythmic starch turnover and abscisic acid (ABA) levels at dawn and dusk. Acta Physiologiae Plantarum, 39(8), 162.

[31] Pretzsch, H., Biber, P., Uhl, E., Dahlhausen, J., Schütze, G., Perkins, D., ... \& Chavanne, A. (2017). Climate change accelerates growth of urban trees in metropolises worldwide. Scientific reports, 7(1), 15403.

[32] Edwards, E. F. (1972). Discharge lamps: some aspects of research and development. Lighting Research \& Technology, 4(3), 117-128.

[33] Girardoz, S., Quicke, D. L., \& Kenis, M. (2007). Factors favouring the development and maintenance of outbreaks in an invasive leaf miner Cameraria ohridella (Lepidoptera: Gracillariidae): a life table study. Agricultural and Forest Entomology, 9(2), 141-158.

[34] Nardini, A., Raimondo, F., Scimone, M., \& Salleo, S. (2004). Impact of the leaf miner Cameraria ohridella on whole-plant photosynthetic productivity of Aesculus hippocastanum: insights from a model. Trees, 18(6), 714-721.

[35] Vogel, G. (2017). Where have all the insects gone? Science, 356(6338), 576-579.

[36] Hallmann, C. A., Sorg, M., Jongejans, E., Siepel, H., Hofland, N., Schwan, H., ... \& Goulson, D. (2017). More than 75 percent decline over 27 years in total flying insect biomass in protected areas. PloS one, 12(10), e0185809.

[37] Grubisic, M., Van Grunsven, R. H. A., Kyba, C. C. M., Manfrin, A., \& Hölker, F. (2018). Insect declines and agroecosystems: does light pollution matter?. Annals of applied biology, 173(2), 180-189.

[38] van Langevelde, F., Braamburg-Annegarn, M., Huigens, M. E., Groendijk, R., Poitevin, O., van Deijk, J. R., ... \& Franzén, M. (2018). Declines in moth populations stress the need for conserving dark nights. Global change biology, 24(3), 925-932.

[39] Augustin, S., Guichard, S., Heitland, W., Freise, J., Svatoš, A., \& Gilbert, M. (2009). Monitoring and dispersal of the invading Gracillariidae Cameraria ohridella. Journal of Applied Entomology, 133(1), 5866.

[40] Kuechly, H. U., Kyba, C. C., Ruhtz, T., Lindemann, C., Wolter, C., Fischer, J., \& Hölker, F. (2012). Aerial survey and spatial analysis of sources of light pollution in Berlin, Germany. Remote Sensing of Environment, 126, 39-50.

[41] Davies, T. W., Bennie, J., \& Gaston, K. J. (2012). Street lighting changes the composition of invertebrate communities. Biology letters, 8(5), 764-767.

[42] Manfrin, A., Singer, G., Larsen, S., Weiß, N., van Grunsven, R. H., Weiß, N. S., ... \& Hölker, F. (2017). Artificial light at night affects organism flux across ecosystem boundaries and drives community structure in the recipient ecosystem. Frontiers in Environmental Science, 5, 61.

[43] Longcore, T., Rodríguez, A., Witherington, B., Penniman, J. F., Herf, L., \& Herf, M. (2018). Rapid assessment of lamp spectrum to quantify ecological effects of light at night. Journal of Experimental Zoology Part A: Ecological and Integrative Physiology, 329(8-9), 511-521.

[44] Hogewoning, S. W., Trouwborst, G., Maljaars, H., Poorter, H., van Ieperen, W., \& Harbinson, J. (2010). Blue light dose-responses of leaf photosynthesis, morphology, and chemical composition of Cucumis sativus grown under different combinations of red and blue light. Journal of experimental botany, 61(11), 3107-3117.

[45] Brelsford, C. C., \& Robson, T. M. (2018). Blue light advances bud burst in branches of three deciduous tree species under short-day conditions. Trees, 32(4), 1157-1164.

[46] Donners, M., van Grunsven, R. H., Groenendijk, D., van Langevelde, F., Bikker, J. W., Longcore, T., \& Veenendaal, E. (2018). Colors of attraction: Modeling insect flight to light behavior. Journal of Experimental Zoology Part A: Ecological and Integrative Physiology, 329(8-9), 434-440.

[47] van Langevelde, F., Ettema, J. A., Donners, M., WallisDeVries, M. F., \& Groenendijk, D. (2011). Effect of spectral composition of artificial light on the attraction of moths. Biological conservation, 144(9), 22742281.

[48] Schroer, S. \& Hölker, F. (2017) Light pollution reduction. Handbook of Advanced Lighting Technology (eds. Karlicek, R., Sun, C.-C., Zissis, G. \& Ma, R.) Springer, Cham, 991-1010 